\title{
Treatment of the mandibular shift in an adult woman and the diagnostic value of joint space index: a case report
}

Kai Xia ${ }^{1,2+}$, Wentian Sun ${ }^{1,2+}$, Liyuan Yu ${ }^{1,2}$, Xinqi Huang ${ }^{1,2}$, Zhihe Zhao ${ }^{1,2}$ and Jun Liu ${ }^{1,2^{*}}$

\begin{abstract}
Background: Mandibular deviations are common clinical complaints. The orthodontic or orthognathic treatment of mandibular deviations is tricky because a comprehensive diagnosis, especially a functional one, is difficult to make. A inaccurate diagnosis may lead to a compromised and unstable treatment outcome.

Case presentation: This article describes the diagnosis and treatment of a woman with a mandibular deviation and facial skeletal asymmetry. By eliminating the disharmony of the arch form with elastics and bite turbos, her esthetic and functional outcomes improved. Cone-beam CT (CBCT) and Joint Space Index (JSI) analyses served as the diagnostic approaches and outcome evaluation methods before and after treatment.
\end{abstract}

Conclusions: A condyle position displacement could be an indication of functional deviation. JSI analysis is a quantitative and convenient choice to compare condyle relative positions.

Keywords: Adult treatment, Asymmetry, Joint space index, Case report

\section{Background}

Mandibular deviations are common malocclusions in orthodontic clinical practice characterized by facial asymmetry and chin and dental midline deviations. The reported prevalence of asymmetries in adults is $44.8 \%$ [1]. Mandibular deviations are one of the essential factors affecting facial attractiveness, especially in terms of lateral displacement of the chin $[1,2]$. Interventions with orthodontic or orthognathic approaches should be carefully chosen according to the extent and the etiology of deviations [3-5]. The etiology factors are generally classified as dental, skeletal, and functional [6]. Comprehensive diagnoses are difficult to make and only become

\footnotetext{
*Correspondence: junliu@scu.edu.cn

${ }^{\dagger}$ Kai Xia and Wentian Sun contributed equally to this work

1 State Key Laboratory of Oral Diseases \& National Clinical Research Center for Oral Diseases, West China Hospital of Stomatology, Sichuan University, No. 14, 3rd Section, South Renmin Road, Chengdu 610041, Sichuan, China

Full list of author information is available at the end of the article
}

trickier for functional diagnoses. If the diagnosis is not accurate, the treatment outcome will be compromised and unstable $[4,7]$. This case report describes the diagnosis and treatment of a woman with a functional mandible deviation and facial asymmetry. Using cone-beam CT (CBCT) and a Joint Space Index (JSI) analysis, we arrived at a reliable diagnosis to guide the choice of treatment. Treatment with elastics and bite turbos finally resolved her deviation by eliminating the disharmony of the arch form and relocation of the condyles. The treatment improved her esthetics and function, what is more, a promising diagnostic method for functional deviations deserves more attention.

\section{Case presentation Diagnosis and etiology}

The patient was 23-year-old healthy woman with chief complaints of a mandibular deviation and crowded dentition. The facial evaluation showed an asymmetric face with a mandible shift to the right side and a 
soft-tissue asymmetry. A convex profile and a deep mentolabial sulcus were noted. The maxillary dental midline was coincident with the facial midline; whereas, the mandibular dental midline deviated $1.5 \mathrm{~mm}$ to the right. Intraorally, a half-step Class II molar and canine relationship was observed on the right; a Class I molar and canine relationship was observed on the left. The dentition was mildly crowded in both arches with a 5-mm overbite and a 4-mm overjet (Fig. 1). The dental cast analysis showed a normal Bolton index but a disharmonious arch width between the maxillary and mandibular arch: the mandibular arch width was $1.5 \mathrm{~mm}$ wider than the maxillary arch in the premolar region. A reduced vertical height of the posterior region on the right side was observed (Fig. 2). The cephalometric analysis showed a normal vertical skeletal pattern (Frankfort-mandibular plane angle (FMA), $28.2^{\circ}$; sella-nasion to Gonion-Gnathion angle (SN-GoGn), $33.5^{\circ}$ ) and a mild Class II sagittal pattern (sella-nasion A-point angle (SNA), 82.9; sellanasion B-point angle (SNB), 79.0; A-point-nasionB-point angle (ANB), 3.9). The incisors were slightly retruded in the maxillary and mandibular regions (interincisal angle, $134.6^{\circ} ; 102.3^{\circ}$ from the maxillary incisor to $\mathrm{SN}$; incisor mandibular plane angle (IMPA), $89.6^{\circ}$ ). The JSI was calculated with $\mathrm{CBCT}$ as previously described [8]. The JSI of the right condyle was smaller than that of the left (right, -30.7 , left, -8.7 ), which meant that the right condyle was in a more posterior position than the left condyle (Fig. 3; Table 1, 2). The three-dimensional reconstruction of the CBCT image showed that a right-deviated mandible (skeletal landmarks sella, basion, and anterior nasal spine were used as midsagittal plane reference to orient $\mathrm{CBCT}$ images and measure asymmetry [9]), the ramus, body, and total length of the right side were mildly shorter than

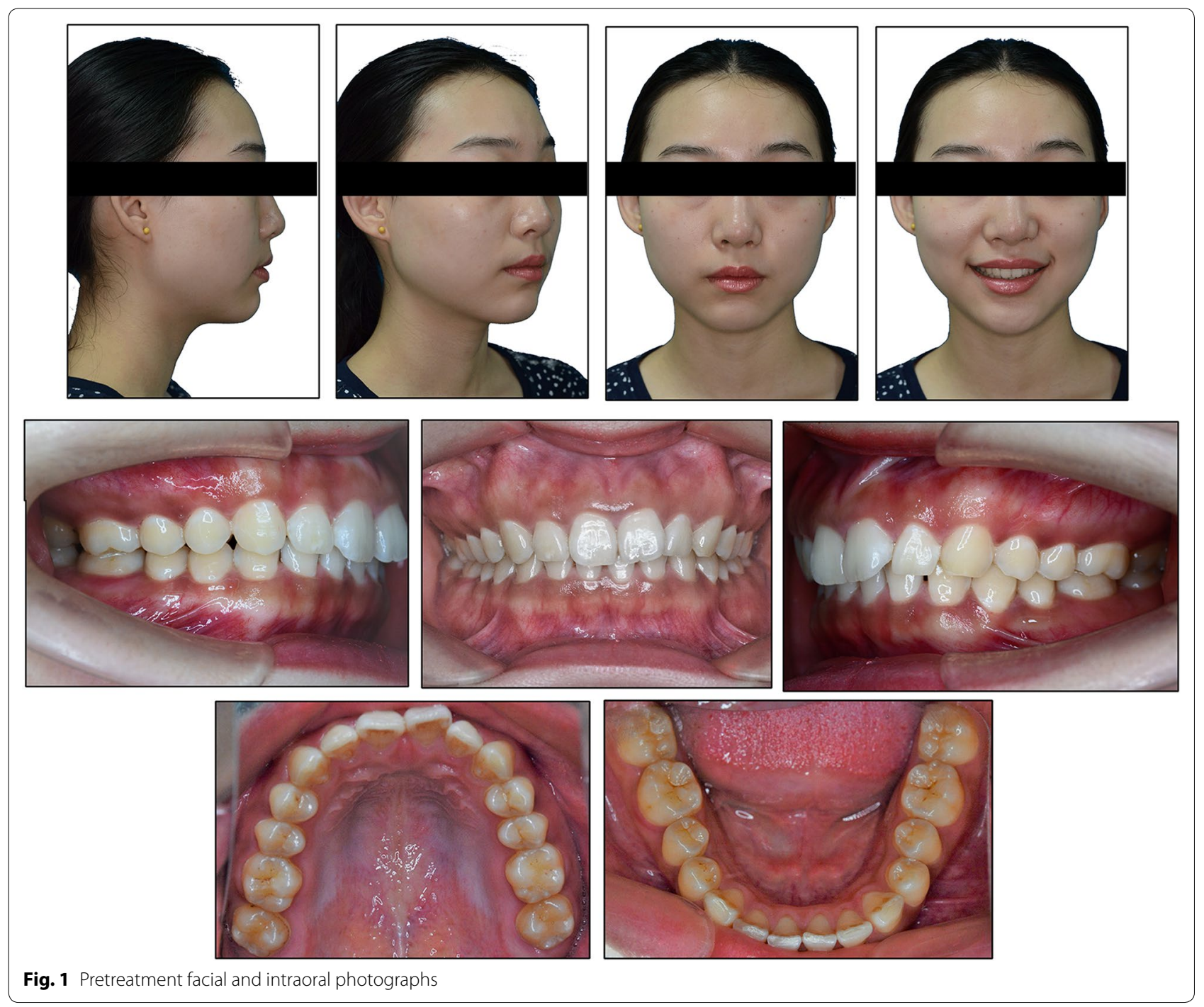



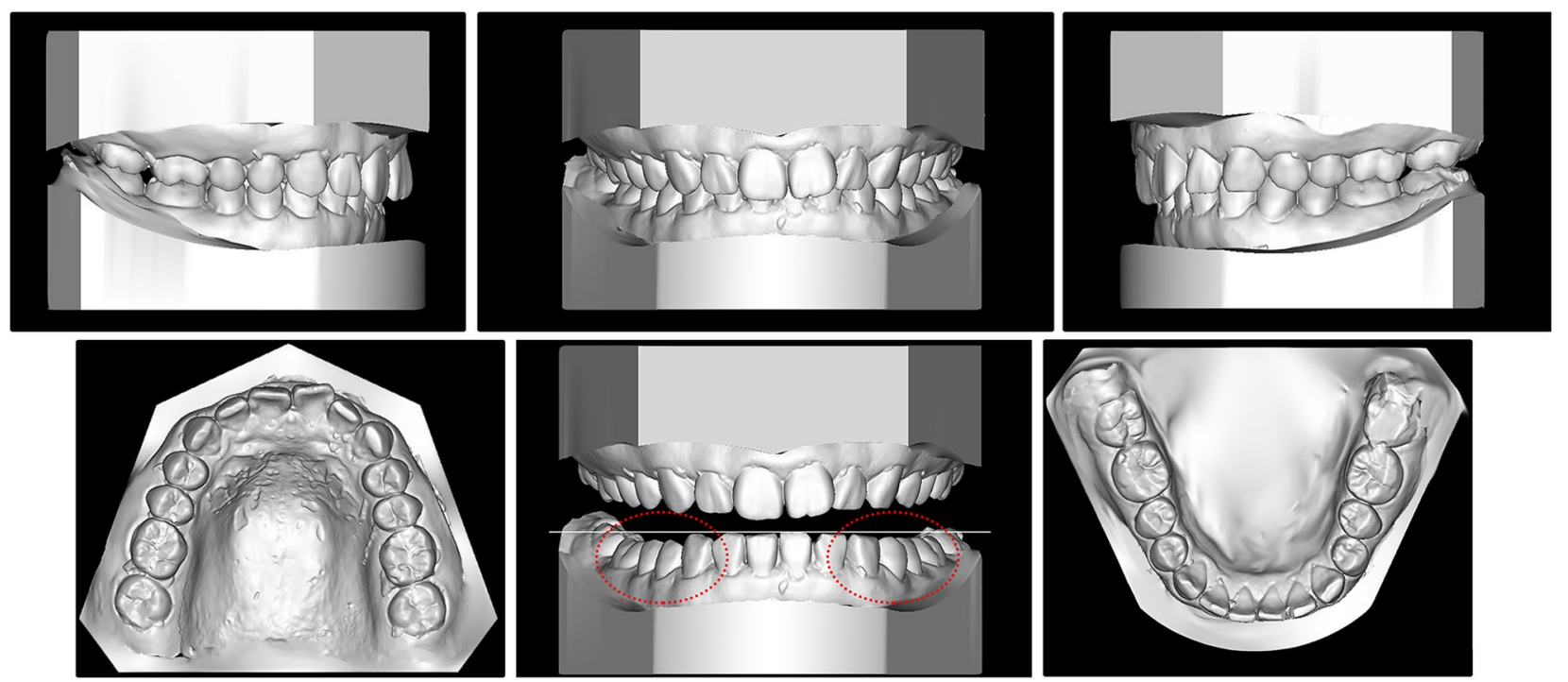

Fig. 2 Pretreatment dental casts
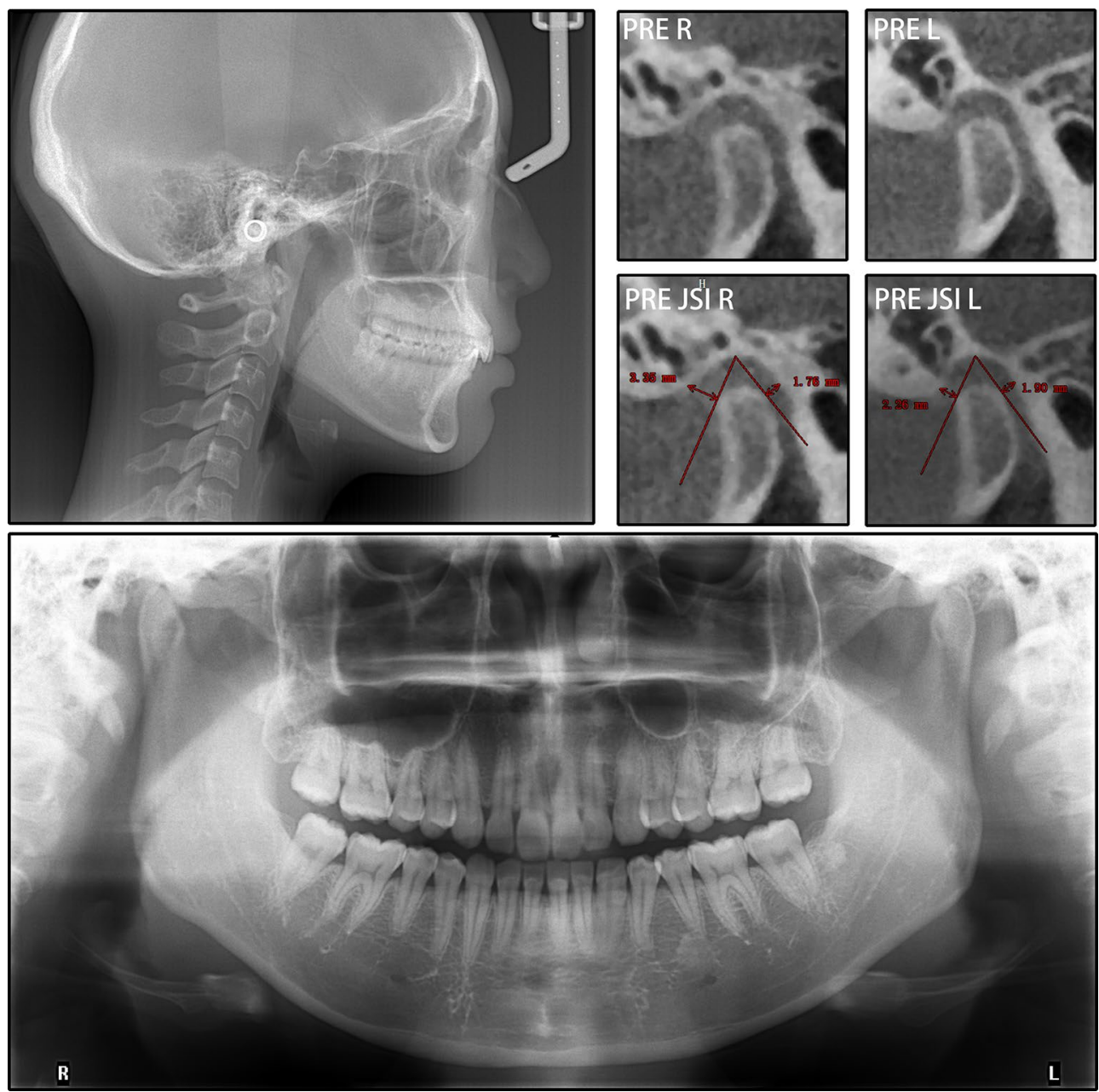

Fig. 3 Pretreatment radiographs and bilateral TMJ JSIs 
Table 1 Cephalometric measurements

\begin{tabular}{|c|c|c|c|}
\hline Measurement & Normal & $\begin{array}{l}\text { Before } \\
\text { treatment }\end{array}$ & After treatment \\
\hline $\operatorname{SNA}\left({ }^{\circ}\right)$ & $81.7 \pm 2.5$ & 82.9 & 82.5 \\
\hline $\mathrm{SNB}\left({ }^{\circ}\right)$ & $78.9 \pm 2.2$ & 79.0 & 78.9 \\
\hline $\operatorname{ANB}\left({ }^{\circ}\right)$ & $2.8 \pm 1.2$ & 3.9 & 3.6 \\
\hline $\mathrm{SN}-\mathrm{MP}\left({ }^{\circ}\right)$ & $32.9 \pm 4.2$ & 33.5 & 34.5 \\
\hline FMA $\left(^{\circ}\right)$ & $29.0 \pm 3.5$ & 28.2 & 29.3 \\
\hline Y-axis $\left({ }^{\circ}\right)$ & $63.5 \pm 3.2$ & 64.1 & 64.9 \\
\hline S-Go/N-Me & $65.9 \pm 3.8$ & 63.3 & 62.8 \\
\hline ANS-Me/N-Me & $53.3 \pm 1.8$ & 57.5 & 57.7 \\
\hline U1-L1 $\left(^{\circ}\right)$ & $123.2 \pm 6.2$ & 134.6 & 129.5 \\
\hline U1-SN $\left({ }^{\circ}\right)$ & $105.1 \pm 6.2$ & 102.3 & 103.7 \\
\hline $\operatorname{IMPA}\left({ }^{\circ}\right)$ & $95.4 \pm 4.7$ & 89.6 & 92.3 \\
\hline UL-EP (mm) & $-0.5 \pm 1.9$ & -1.9 & -2.0 \\
\hline LL-EP (mm) & $1.3 \pm 1.9$ & 1.3 & 1.53 \\
\hline Z angle $\left({ }^{\circ}\right)$ & $74.1 \pm 4.6$ & 68.3 & 69.5 \\
\hline
\end{tabular}

$S$ sella, $N$ nasion, A A-point, B B-point, MP mandibular plane, $S N$ sella-nasion plane, FMA Frankfort-mandibular plane angle, IMPA incisor mandibular plane angle, EP esthetic plane, UL upper lip, LL lower lip

those of the left side (Fig. 4; Table 3). That is, her deviation presented both functional and skeletal factors.

\section{Treatment objectives}

With a focus on the patient's chief complaints, the primary objectives of treatment were to coordinate the dental midlines and correct the asymmetrical facial appearance. The other treatment objectives were to resolve the dental crowding, establish normal overbite and overjet relationships, and obtain an ideal occlusion.

\section{Treatment alternatives}

The patient was told that if orthodontic treatment could not correct her asymmetric appearance, surgery could be an alternative choice. However, because of the surgical risks and costs of surgical intervention, surgical treatment was not recommended for this patient.

\section{Treatment progress}

To meet her esthetic demand, a ceramic preadjusted bracket (0.022-inch slot, Damon Clear; Ormco, Orange, CA) was placed on the labial side of both arches. A 0.014inch round nickel-titanium wire was used to initiate alignment. At 7 months, a $0.018 \times 0.025$-inch stainless steel working wire and a 0.014 -inch round nickel-titanium wire were placed in the upper and lower arch, respectively. Bite turbos were added to the occlusal surfaces of the mandibular right first molar and left molars to control the vertical height of the lower molars (Fig. 5). After 5 months, both arches were leveled and aligned, and the arch forms were coordinated by matching the archwires with archform chart. A unilateral Class II elastic (Penguin, 5/16-in, 3.5-oz; Ormco) and an anterior diagonal elastic (Penguin, 5/16-in, 3.5-oz; Ormco) were used from the upper right side to the lower left side to correct the mandibular functional shift (Fig. 6). Furthermore, the bite turbos on the mandibular right first molar were progressively reduced to reestablish a normal vertical dimension and ideal bilateral occlusion. After 8 months, the dental midlines were coordinated with Class I molar and canine relationships, and the use of the elastics was stopped. Short-term efficacy stability was observed for another 3 months before removing the fixed appliances. The treatment period was 24 months, and a Hawley retainer was used for retention.

\section{Treatment results}

Class I molar and canine relationships with coincident dental and facial midlines and adequate overbite and overjet relationships were achieved. The facial photographs showed a symmetrical appearance (Fig. 7). The dental cast analysis indicated that the maxillary interpremolar (14-24) and intermolar (16-26) widths increased by $2.3 \mathrm{~mm}$ and $1.3 \mathrm{~mm}$, respectively, and that the arch forms were coordinated between the two arches. The reduced vertical height of the right posterior region was also corrected (Fig. 8). No resorption or deformity in the condylar structure was found with CBCT of the temporomandibular joint (TMJ) regions. The panoramic radiographs showed parallel roots without root resorption (Fig. 9). The superimposition of the cephalometric

Table 2 Bilateral joint space measurements

\begin{tabular}{|c|c|c|c|c|c|c|}
\hline & \multicolumn{3}{|l|}{ Right TMJ } & \multicolumn{3}{|l|}{ Left TMJ } \\
\hline & Anterior JS (mm) & Posterior JS (mm) & JSI & Anterior JS (mm) & Posterior JS (mm) & JSI \\
\hline Pretreatment & 3.35 & 1.76 & -30.7 & 2.26 & 1.90 & -8.7 \\
\hline Posttreatment & 2.59 & 2.96 & 6.7 & 1.47 & 2.44 & 19.4 \\
\hline Relative change (Post-pre) & -0.76 & 1.20 & 37.4 & -0.79 & 0.54 & 28.1 \\
\hline
\end{tabular}

TMJ temporomandibular joint, JS joint space, JSI Joint Space Index 

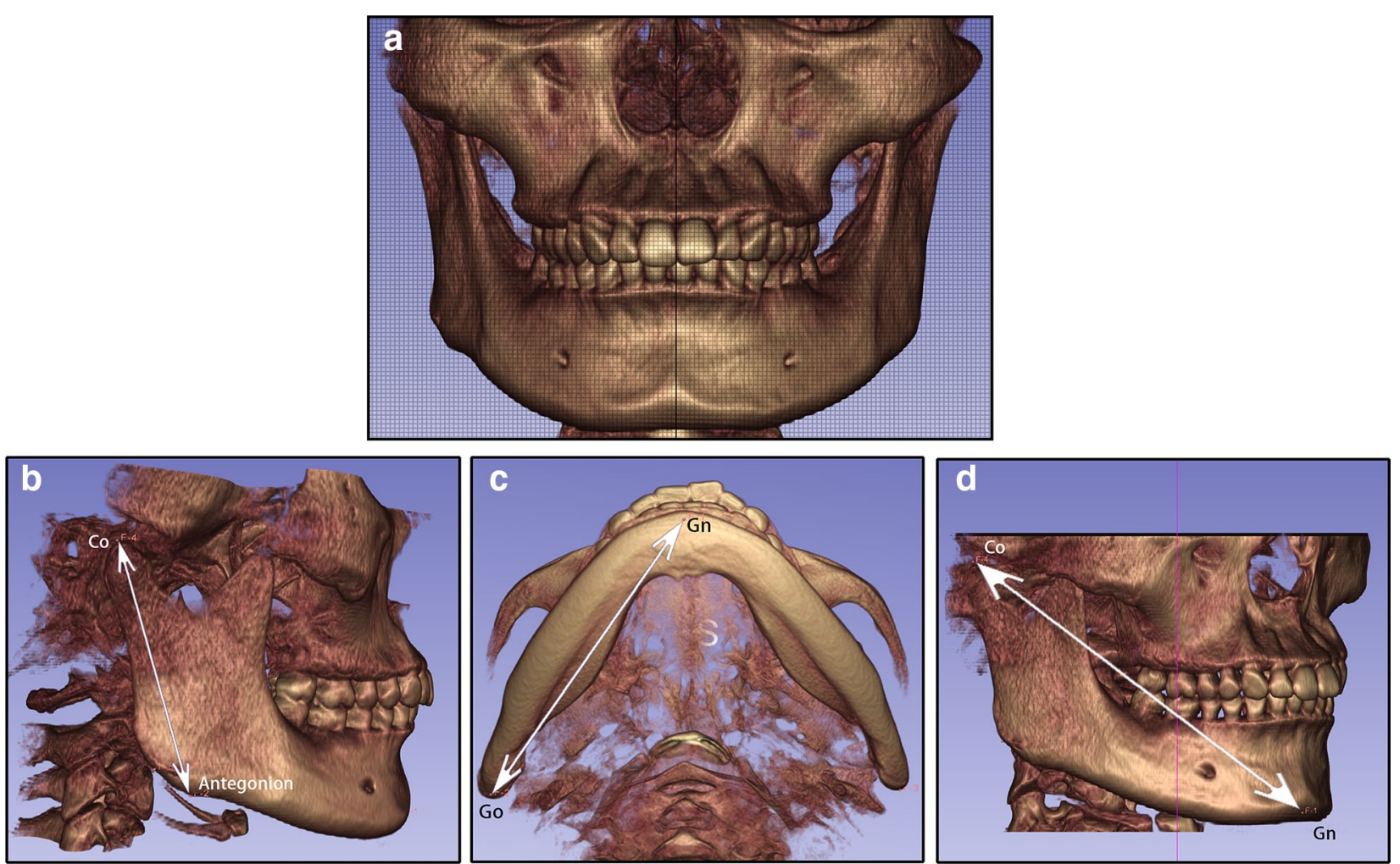

Fig. 4 Three-dimensional reconstructions and measurements of the mandible. a Orientated three-dimensional reconstructions of the craniomaxillofacial complex (The grid has a width of $1 \mathrm{~mm}$ ) showed that the mandible deviated $1.5 \mathrm{~mm}$ to the right. $\mathbf{b}$ The ramus length, $\mathbf{d}$ the body length and $\mathbf{d}$ the total length of the mandible

Table 3 Measurements of the mandible

\begin{tabular}{lllc}
\hline & $\begin{array}{l}\text { Ramus length } \\
(\mathbf{m m})\end{array}$ & $\begin{array}{l}\text { Body length } \\
(\mathbf{m m})\end{array}$ & $\begin{array}{l}\text { Total } \\
\text { length } \\
(\mathbf{m m})\end{array}$ \\
\hline Right mandible & 65.5 & 90.8 & 124.6 \\
$\begin{array}{l}\text { Left mandible } \\
\begin{array}{l}\text { Relative difference } \\
\text { (left-right) }\end{array}\end{array}$ & 66.2 & 91.6 & 125.6 \\
\hline
\end{tabular}

radiographs showed normalization of the incisor inclination. A slight clockwise rotation of the mandibular plane was observed in response to the molar extrusions. A GoGn-oriented superimposition of three-dimensional mandible reconstructions also verified the extrusion. The right lower first molar and left lower first molar extruded $1.8 \mathrm{~mm}$ and $1.1 \mathrm{~mm}$, respectively (Figs. 10 and 11). The JSI of both sides increased after treatment $(\Delta$ right JSI $=37.4$, $\Delta$ left JSI $=28.1$ ), indicating that the right condyle presented a more significant anterior relocation than the left condyle (Fig. 12; Table 2). A three-dimensional superimposition based on cranial base and zygoma showed that asymmetry has improved as the mandible is repositioned back to the left (Fig. 13). The patient was satisfied with the result of the treatment, and did not complain of temporomandibular disorder (TMD) symptoms throughout the treatment period. After 14 months of retention, the patient came for a follow-up. Her symmetrical appearance and occlusion were still stable (Fig. 14).

\section{Discussion}

Dental and facial asymmetries are common chief complaints in orthodontic patients. Class II subdivision malocclusions tend to lead to mandibular midlines not coincident with facial midlines [10]. The causes of this deviation are varied. Cassidy et al. found that most Class II subdivision patients exhibited some degree of mandibular skeletal asymmetry [10]. Li et al. investigated the origin of subdivision asymmetries with $\mathrm{CBCT}$ and dental cast analyses and found that functional factors such as a disharmonious arch width between the maxillary and mandibular dental arches in the premolar section accounted for the majority of the cases [11]. 

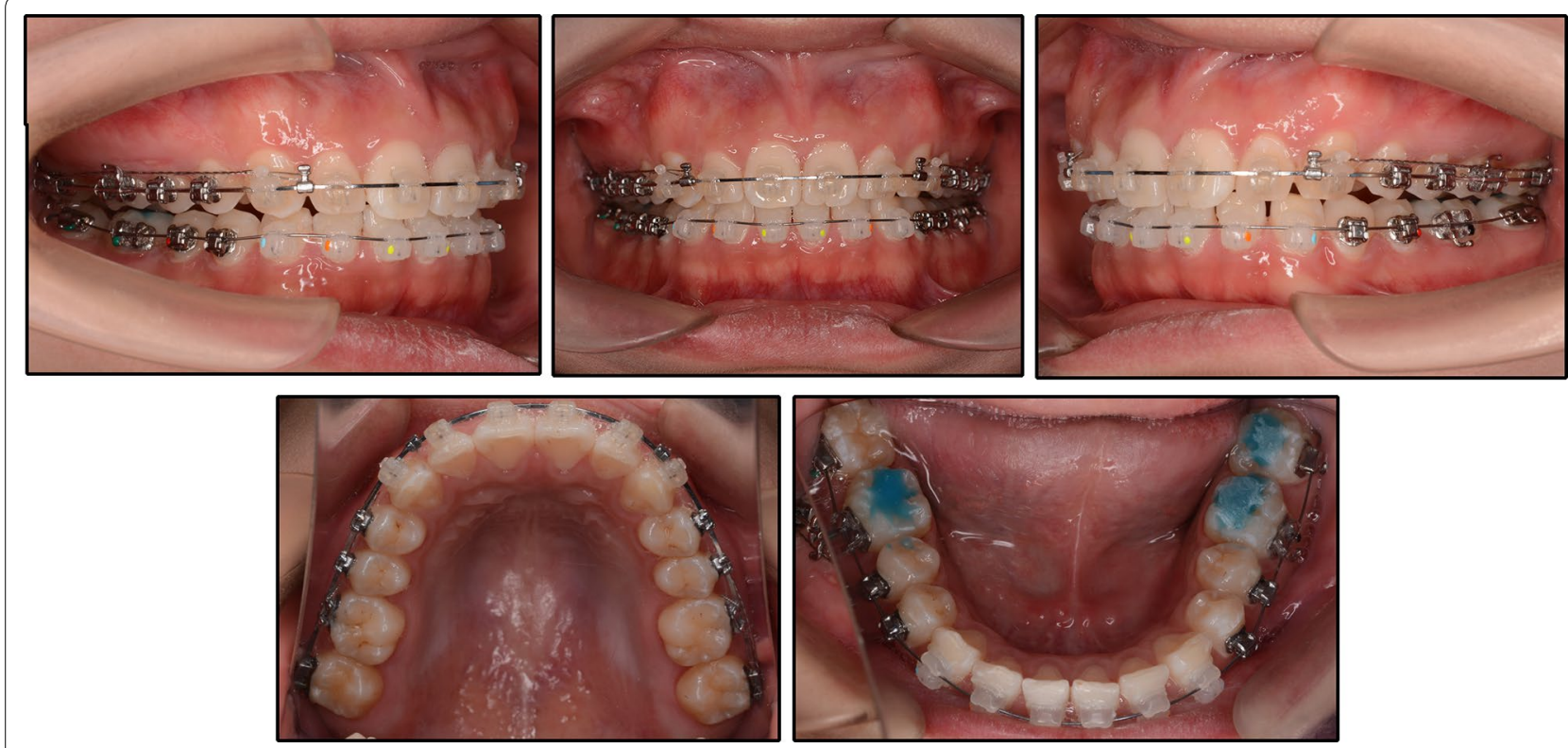

Fig. 5 Intraoral photographs during treatment: Bite turbos were added to control the vertical height of the lower molars
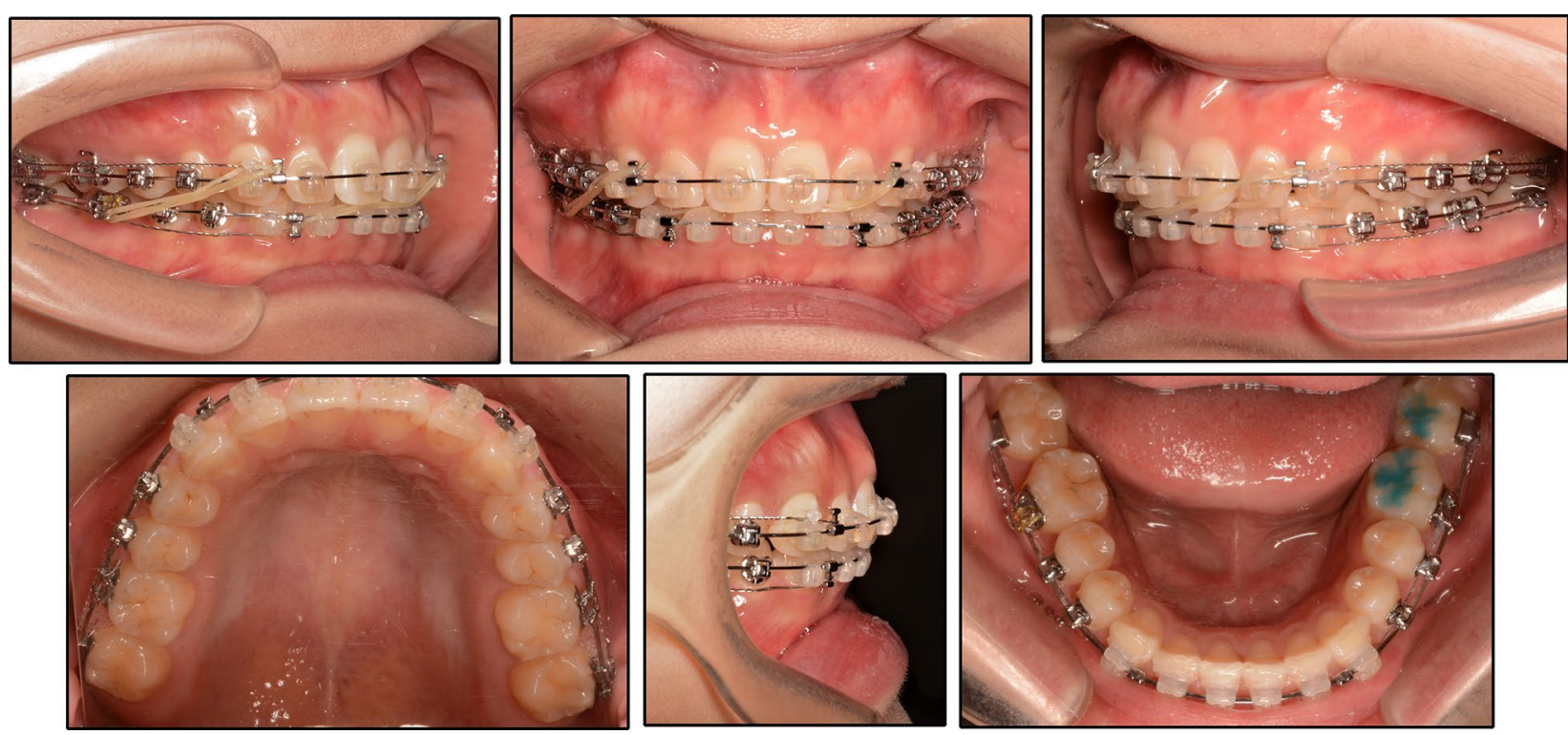

Fig. 6 Intraoral photographs during treatment: A unilateral Class II elastic and an anterior diagonal elastic were used to correct the mandibular functional shift 


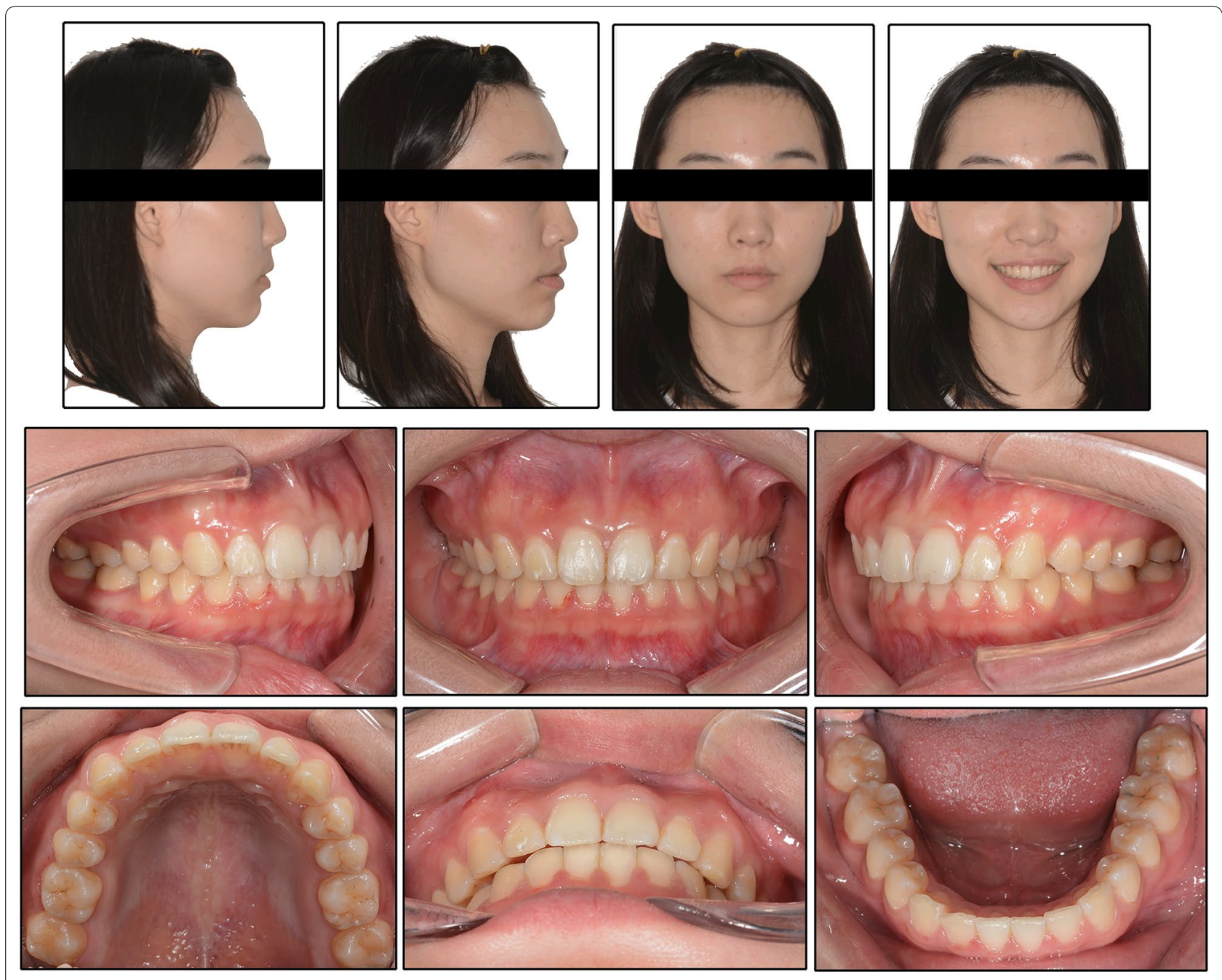

Fig. 7 Post-treatment facial and intraoral photographs
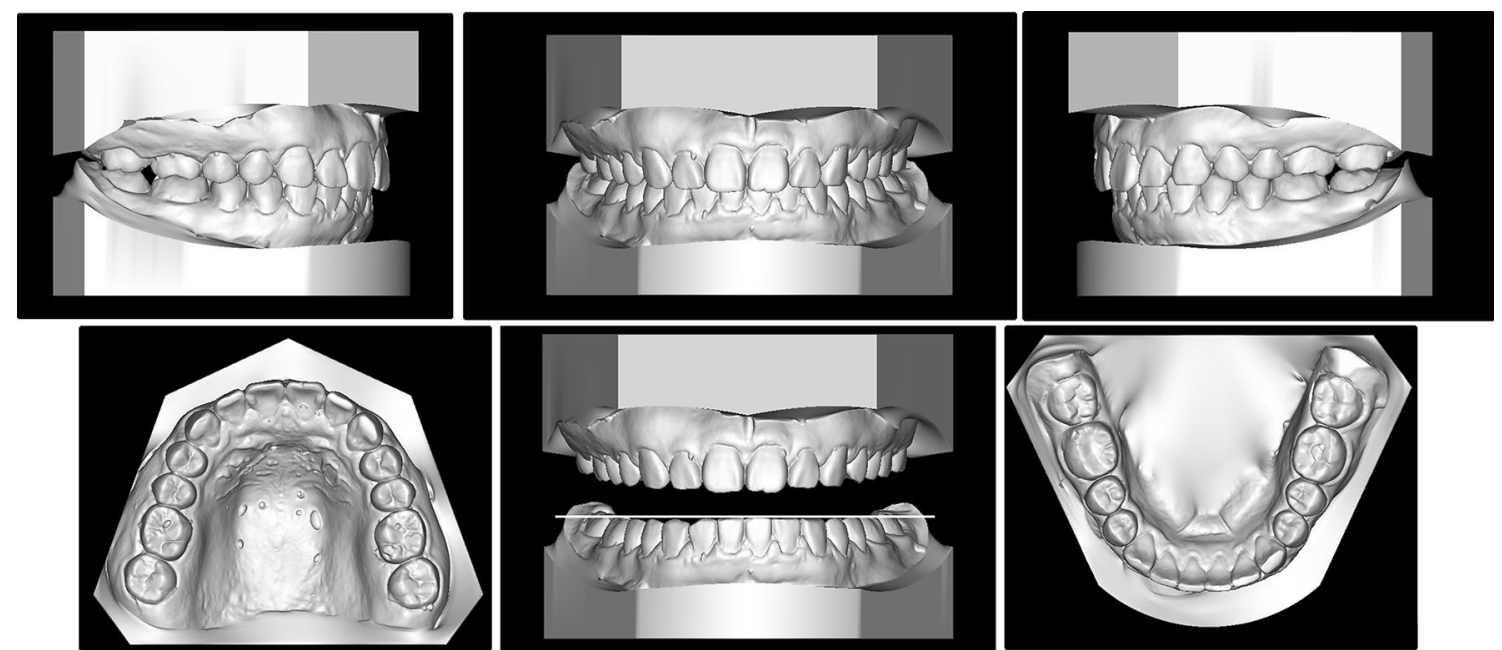

Fig. 8 Post-treatment dental casts 


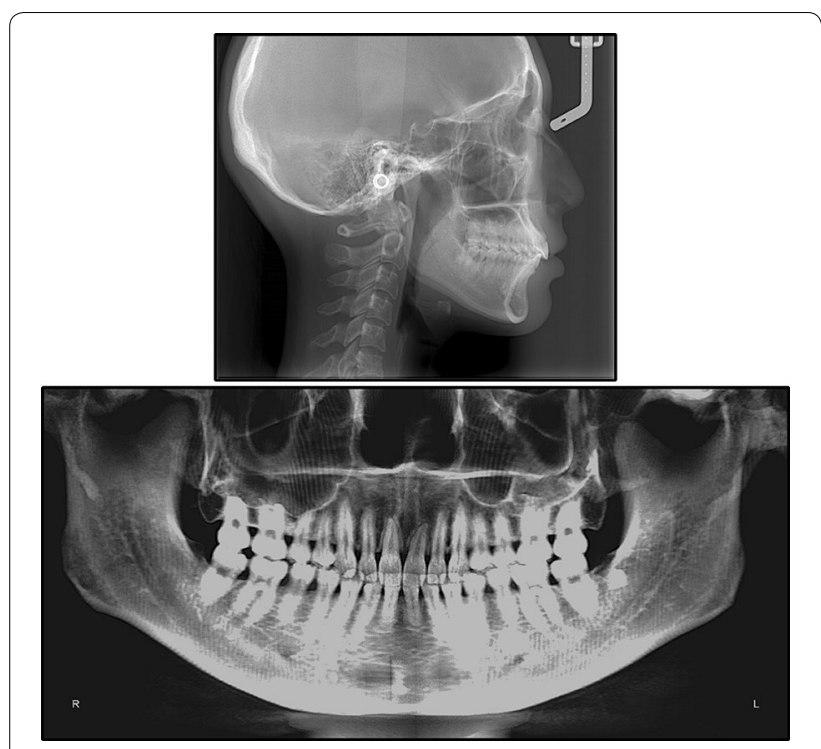

Fig. 9 Post-treatment radiographs

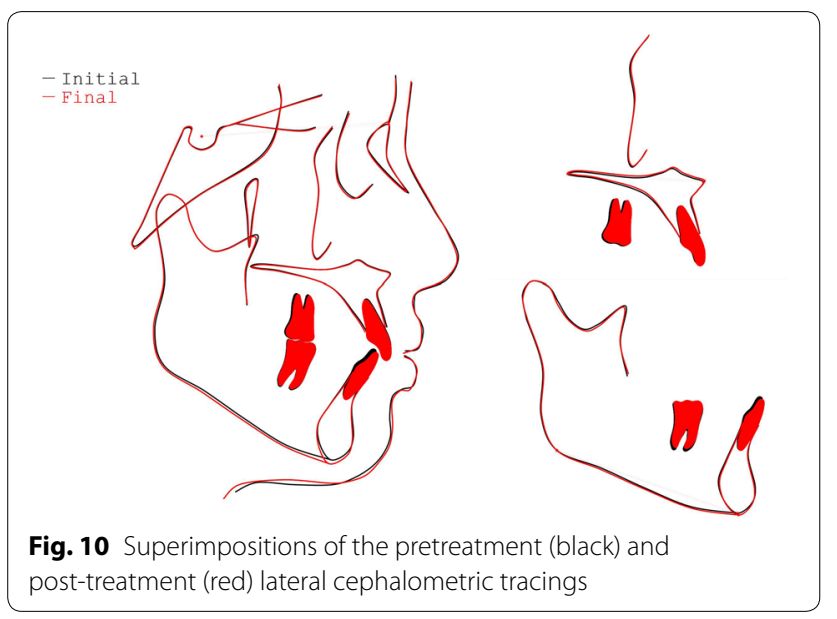

In the diagnosis process, we found that this patient had both skeletal and functional factors by means of JSI analysis and three-dimensional reconstructions, and we speculated that the long-term functional deviation might be the reason for her skeletal deviation, as previous studies indicated [12-15]. Functional deviations are usually examined by observing the coincidence of the dental midlines during mouth closure in the maximum intercuspal position, at initial contact, and at the mandibular rest position. Patients with functional deviations will show midline deviations between the initial contact and mouth closure. As this mild deviation is difficult to detect with direct observations, the condylar position indicator and mandibular monitoring could help to diagnose abnormal condylar position and mandibular movements [16-18]. However, the dentofacial complex shows exceptional adaptability to functional demands. A previous study indicated that this ability to adapt to functional deviations of the mandible leads to a functional rebalance $[19,20]$. That is, long-term mandibular functional shifts and the associated mechanically forced displacement of the mandible in the closure path may be compensated by neuromuscular adaption. In clinical manifestations, the mandible directly moves into the intercuspal position (ICP) without interference from the teeth, and a mandibular midline deviation exists, regardless of the jaw position.

As different types of malocclusion have varying degrees of condyle displacement [21, 22], we predicted that the long-term mandibular functional shift also led to condyle displacement and that the condyle finally relocated because of a neuromuscular adaption. Since the centric relation (CR) theory was put forth, most of the controversies were related to the position of the condyle in the glenoid fossa, which is clinically invisible [23]. What is more, there is no established "gold standard" method of CR registration with high repeatability and operability [24]. To directly assess the condylar position, radiological evaluation is a preferable manner [25-27]. Magnetic resonance images (MRI) can be used to evaluate the position of the condyle and disk in the fossa, but it can not be commonly performed in oral clinical practice due to its accessibility and cost problems. With the advent of CBCT, high-definition and sensitive measurements of the condyle position became possible $[26,28,29]$. The combination of CBCT and JSI analysis enables a quantitative and convenient comparison of the relative condyle positions [30]. Research suggested that the physiologic JSI range for the condylar position is -32.5 to 21.1 [31]. In this patient, the condyle on the shifted side (right) was in a posterior position on her first visit (JSI: right, -30.7 , and left, -8.7 ). After the treatment, the right condyle was located in a relatively anterior position, and the mandible shift was also corrected (JSI: right, 6.7, and left, 19.4). Both 


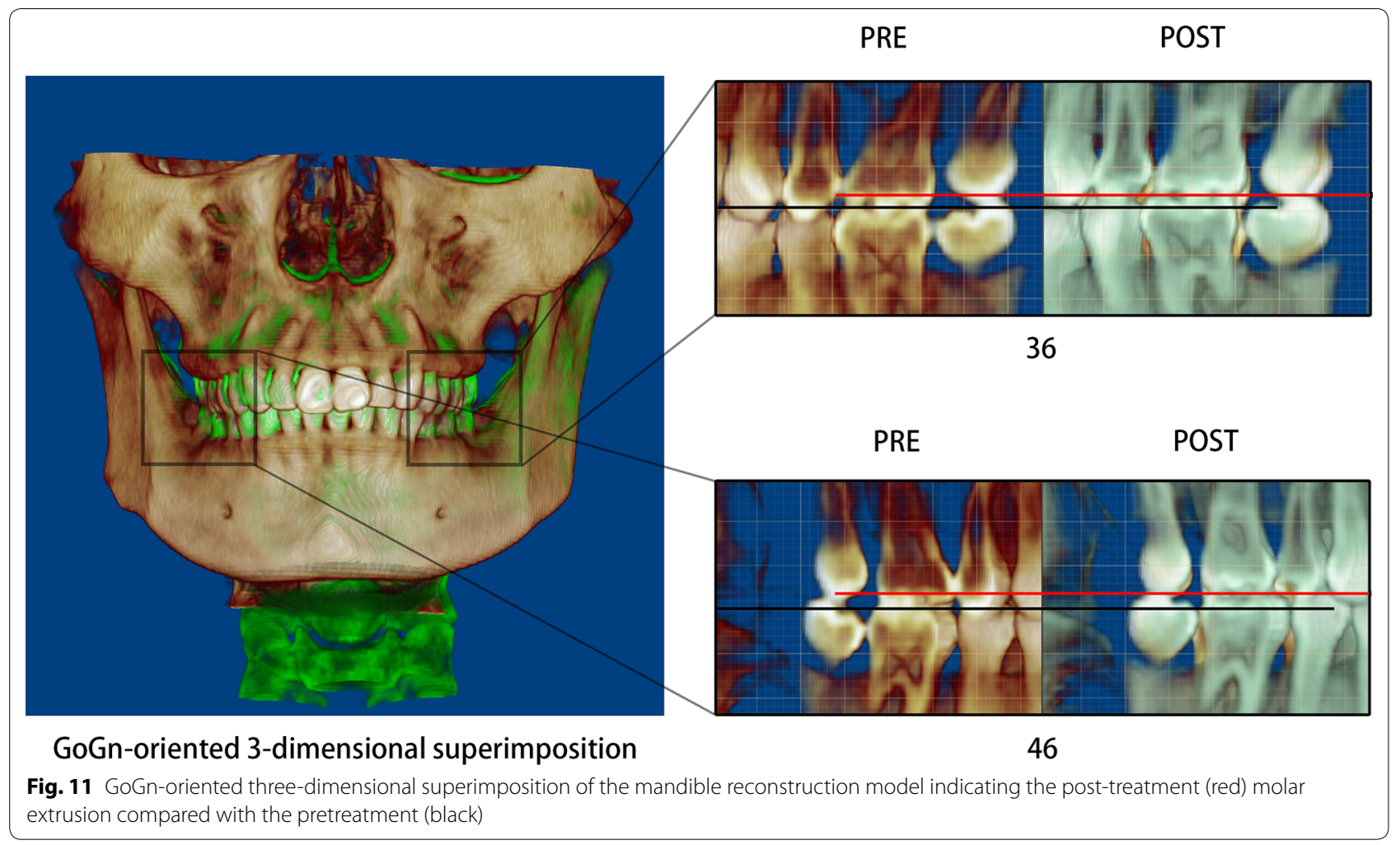

condyles relocated anteriorly to the central position of the glenoid fossa, which is considered a relatively physiologic position [32].

Park et al. reported that mandible skeletal asymmetry presents dental compensation, such as vertical movement of the molars and a transverse cant of the occlusal plane [4]. Ishizaki et al. indicated that a reduced vertical height of the dentition on one side induces a mandibular lateral shift in a three-dimensional rotational manner [33]. Dental decompensation is an important part of mandible deviation treatment; otherwise, the effect will be compromised. With the use of bite turbo and unilateral Class II elastics in this patient, the reduced vertical height of the right posterior region was corrected. The bite turbo in the posterior area served two purposes: (1) to avoid the cusp-to-cusp contact and consequent unstable jaw position, and (2) to control the vertical height of the molar region with masticatory forces on the left side. In addition, a gradual reduction of the bite turbo thickness on the right side in combination with the elastics led to the vertical height recovery.

The molar was slightly extruded as a consequence of the reverse-curve arch wire. The sella-nasion mandibular plane angle (SN-MP) consequently increased by $1^{\circ}$ due to the clockwise mandibular rotation. Interestingly, this rotation did not worsen the skeletal Class II relationships as the ANB remained unchanged. The repositioning of the condyle might compensate for this trend.

The newly acquired condyle and jaw position was retained with intercuspation occlusion. The skeletal facial asymmetry was partly compensated for by the recovery of the mandibular functional shift, as previously reported [34]. The treatment outcome was favorable after 14 months of retention. For functional 


\section{a}
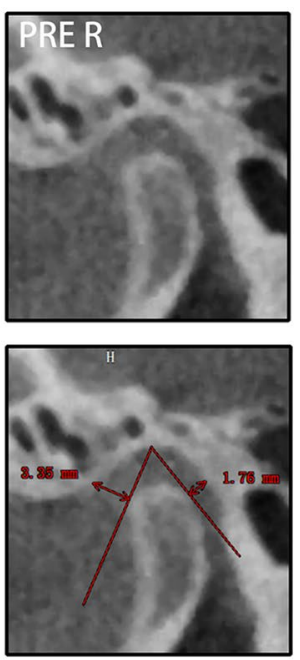

b
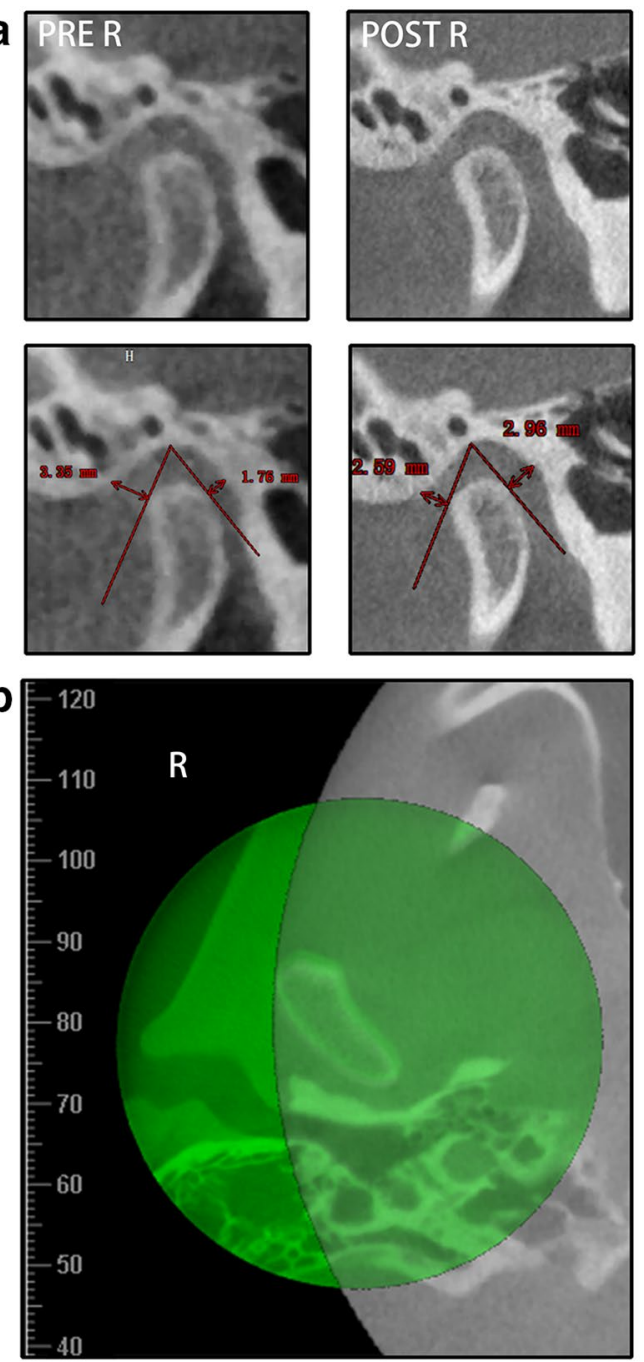
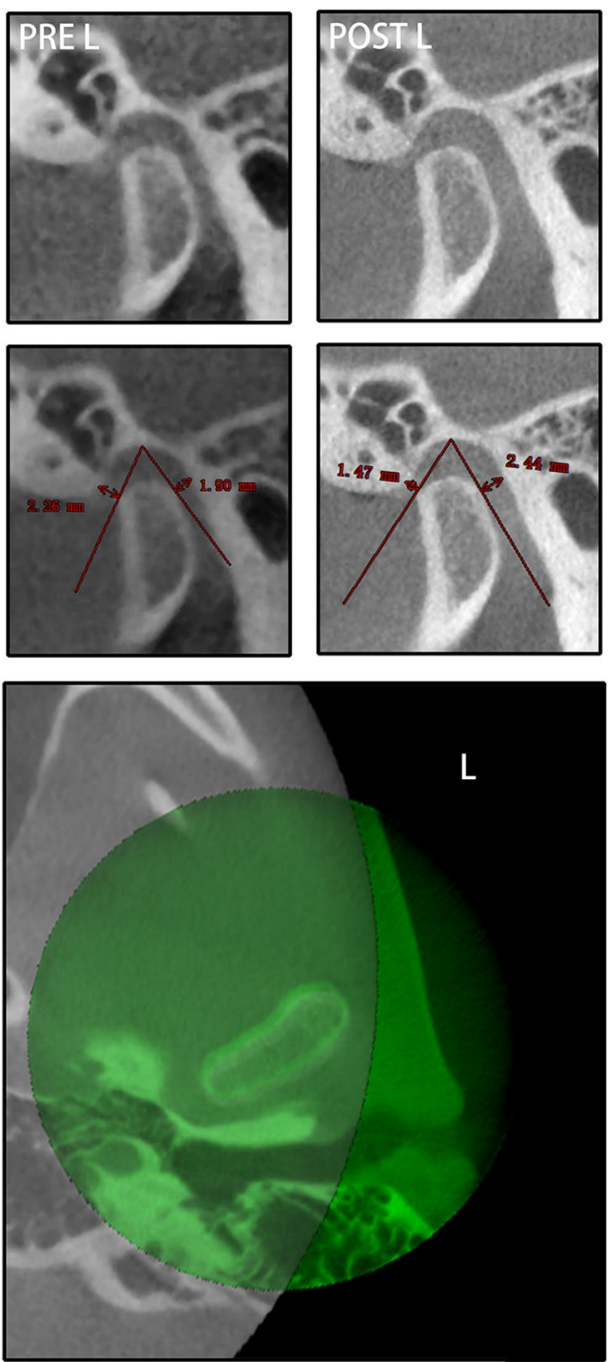

Fig. 12 a Comparison of the pretreatment and post-treatment bilateral TMJ JSIs. b CBCT superimposition of the pretreatment (gray) and post-treatment (green) bilateral TMJs

deviation patients, wearing a Hawley retainer during the day for the first year and tooth positioner at night for 2-3 years could be an effective approach to stabilize the jaw position for retention.

In conclusion, the typical clinical manifestations of functional deviations are not easily observed, as they might be compensated by neuromuscular adaption. In this case, a condyle position displacement could be an indication of functional deviation. JSI analysis is a quantitative and convenient choice to compare condyle relative positions. Furthermore, the recovery of the vertical height in the molar region should be considered as an important part in the mandibular functional deviation treatment process.

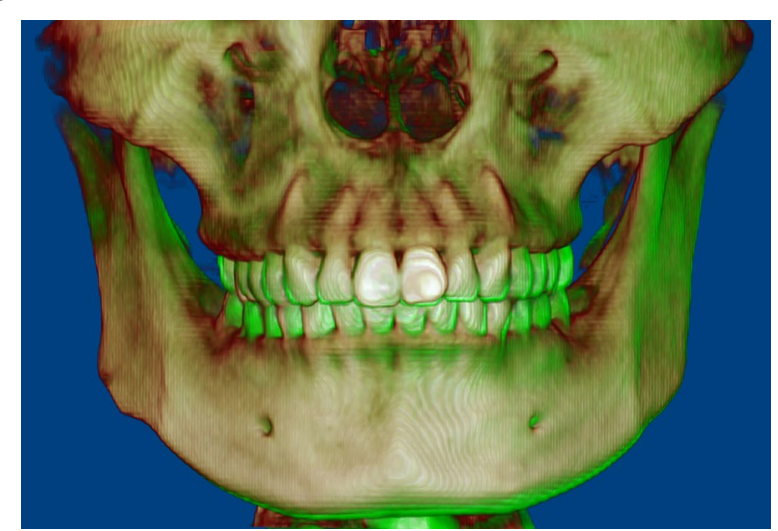

Fig. 13 The three-dimensional superimposition based on cranial base and zygoma showed that the post-treatment (green) mandible is repositioned back to the left compared with the pretreatment (beige) 


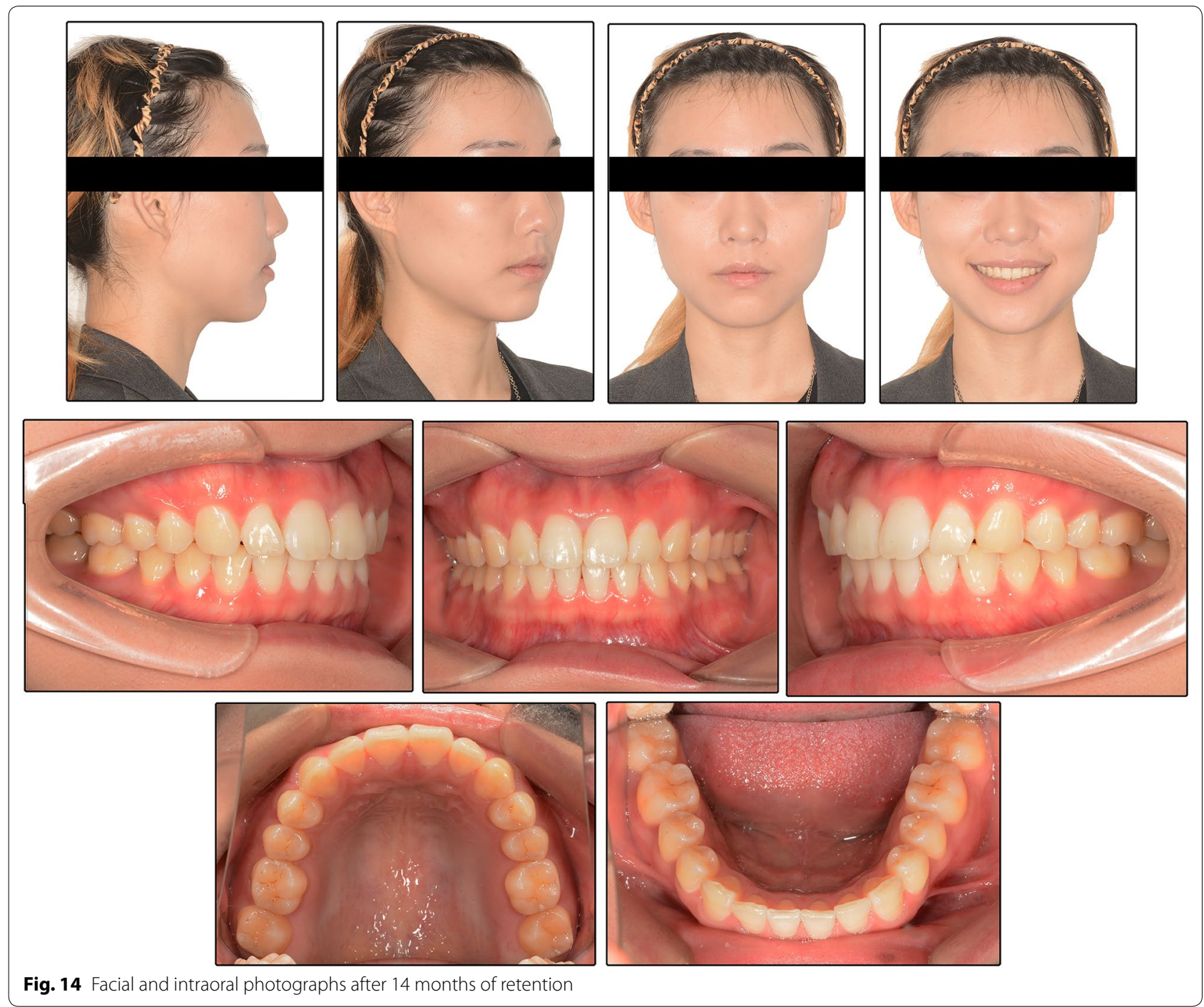

\section{Abbreviations}

CBCT: Cone-beam computed tomography; JSI: Joint space index; ICP: Intercuspal position; CR: Centric relation.

\section{Acknowledgements}

Not applicable.

\section{Authors' contributions}

$J \mathrm{~L}$ and $\mathrm{ZZ}$ designed this study; $\mathrm{KX}$ and WS analyzed the data and drafted the manuscript; $\mathrm{LY}$ and $\mathrm{XH}$ revised the manuscript. All authors read and approved the final manuscript.

\section{Funding}

This study was supported by grant from the National Natural Science Foundation of China (81870743).

\section{Availability of data and materials}

The data that support the findings of this study are available from the corresponding author upon reasonable request.

\section{Ethics approval and consent to participate}

Written informed consent was obtained from the patient for publication of this case report and any accompanying images. A copy of the written consent is available for review by the Editor-in-Chief of this journal. Since no human experimentation was performed, no approval by an ethics board was required.

\section{Consent for publication}

The written informed consent for publication was obtained from the patient.

\section{Competing interests}

The authors declare no conflicts of interest.

\section{Author details}

${ }^{1}$ State Key Laboratory of Oral Diseases \& National Clinical Research Center for Oral Diseases, West China Hospital of Stomatology, Sichuan University, No. 14, 3rd Section, South Renmin Road, Chengdu 610041, Sichuan, China. ${ }^{2}$ Department of Orthodontics, West China Hospital of Stomatology, Sichuan University, No. 14, 3rd Section, South Renmin Road, Chengdu 610041, Sichuan, China. 
Received: 16 July 2020 Accepted: 8 October 2020

Published online: 22 October 2020

\section{References}

1. Thiesen G, Gribel BF, Freitas MPM, Oliver DR, Kim KB. Mandibular asymmetries and associated factors in orthodontic and orthognathic surgery patients. Angle Orthod. 2018:88:545-51.

2. Kaipainen AE, Sieber KR, Nada RM, Maal TJ, Katsaros C, Fudalej PS. Regional facial asymmetries and attractiveness of the face. Eur J Orthod. 2016;38:602-8

3. Gao X, Wang T, Song J. Orthodontic and surgical management of a patient with severe skeletal Class II deformity and facial asymmetry: a case report with a 5-year follow-up. Am J Orthod Dentofacial Orthop. 2017;151:779-92

4. Kim HJ, Hong M, Park HS. Analysis of dental compensation in patients with facial asymmetry using cone-beam computed tomography. Am J Orthod Dentofacial Orthop. 2019;156:493-501.

5. Schmid W, Mongini F. Factors in craniomandibular asymmetry: diagnostic principles and therapy. Mondo ortodonticol. 1990;15:91-104.

6. Bishara SE, Burkey PS, Kharouf JG. Dental and facial asymmetries: a review. Angle Orthod. 1994;64:89-98.

7. Nojima K, Yokose T, Ishii T, Kobayashi M, Nishii Y. Tooth axis and skeletal structures in mandibular molar vertical sections in jaw deformity with facial asymmetry using MPR images. Bull Tokyo Dent Coll. 2007;48:171-6.

8. Ruf S, Pancherz H. Temporomandibular joint growth adaptation in Herbst treatment: a prospective magnetic resonance imaging and cephalometric roentgenographic study. Eur J Orthod. 1998;20:375-88.

9. Green MN, Bloom JM, Kulbersh R. A simple and accurate craniofacial midsagittal plane definition. Am J Orthod Dentofacial Orthop. 2017;152:355-63.

10. Cassidy SE, Jackson SR, Turpin DL, Ramsay DS, Spiekerman C, Huang GJ. Classification and treatment of Class II subdivision malocclusions. Am J Orthod Dentofacial Orthop. 2014;145:443-51.

11. Li J, He Y, Wang Y, Chen T, Xu Y, Xu X, et al. Dental, skeletal asymmetries and functional characteristics in Class II subdivision malocclusions. J Oral Rehabil. 2015:42:588-99.

12. Fuentes MA, Opperman LA, Buschang P, Bellinger LL, Carlson DS, Hinton RJ. Lateral functional shift of the mandible: Part I. Effects on condylar cartilage thickness and proliferation. Am J Orthod Dentofacial Orthop. 2003:123:153-9.

13. Fuentes MA, Opperman LA, Buschang P, Bellinger LL, Carlson DS, Hinton RJ. Lateral functional shift of the mandible: Part II. Effects on gene expression in condylar cartilage. Am J Orthod Dentofacial Orthop. 2003:123:160-6

14. Kokai S, Yabushita T, Zeredo JL, Toda K, Soma K. Functional changes of the temporomandibular joint mechanoreceptors induced by a lateral mandibular shift in rats. Angle Orthod. 2007;77:436-41.

15. Sato C, Muramoto T, Soma K. Functional lateral deviation of the mandible and its positional recovery on the rat condylar cartilage during the growth period. Angle Orthod. 2006;76:591-7.

16. Adly MS, Adly AS, Adly AS. Assessment of early orthodontic treatment on functional shifts by telemonitoring mandibular movements using a smart phone. J Telemed Telecare. 2018;26:150-60.

17. Crawford SD. Condylar axis position, as determined by the occlusion and measured by the CPI instrument, and signs and symptoms of temporomandibular dysfunction. Angle Orthod. 1999;69:103-15.
18. Hidaka O, Adachi S, Takada K. The difference in condylar position between centric relation and centric occlusion in pretreatment Japanese orthodontic patients. Angle Orthod. 2002;72:295-301.

19. McNamara JA Jr. Neuromuscular and skeletal adaptations to altered function in the orofacial region. Am J Orthod Dentofacial Orthop. 1973;64:578-606.

20. Nerder PH, Bakke M, Solow B. The functional shift of the mandible in unilateral posterior crossbite and the adaptation of the temporomandibular joints: a pilot study. Eur J Orthod. 1999;21:155-66.

21. Gorucu-Coskuner H, Ciger S. Computed tomography assessment of temporomandibular joint position and dimensions in patients with class II division 1 and division 2 malocclusions. J Clin Exp Dent. 2017:9:e417-23.

22. Katsavrias EG, Halazonetis DJ. Condyle and fossa shape in Class II and Class III skeletal patterns: a morphometric tomographic study. Am J Orthod Dentofacial Orthop. 2005;128:337-46.

23. Palaskar JN, Murali R, Bansal S. Centric relation definition: a historical and contemporary prosthodontic perspective. J Indian Prosthodont Soc. 2013;13:149-54.

24. Swenson AL, Oesterle LJ, Shellhart WC, Newman SM, Minick G. Condylar positions generated by five centric relation recording techniques. Oral Biol Dent. 2014;2:8

25. Ikeda K, Kawamura A. Disc displacement and changes in condylar position. Dentomaxillofac Radiol. 2013;42:84227642.

26. Ikeda K, Kawamura A, Ikeda R. Assessment of optimal condylar position in the coronal and axial planes with limited cone-beam computed tomography. J Prosthodont. 2011;20:432-8.

27. Imanimoghaddam M, Madani AS, Mahdavi P, Bagherpour A, Darijani M, Ebrahimnejad H. Evaluation of condylar positions in patients with temporomandibular disorders: a cone-beam computed tomographic study. Imaging Sci Dent. 2016;46:127-31.

28. Honey OB, Scarfe WC, Hilgers MJ, Klueber K, Silveira AM, Haskell BS, et al. Accuracy of cone-beam computed tomography imaging of the temporomandibular joint: comparisons with panoramic radiology and linear tomography. Am J Orthod Dentofacial Orthop. 2007;132:429-38.

29. Tsiklakis K, Syriopoulos K, Stamatakis H. Radiographic examination of the temporomandibular joint using cone beam computed tomography. Dentomaxillofac Radiol. 2004;33:196-201.

30. Kamelchuk LS, Grace MG, Major PW. Post-imaging temporomandibular joint space analysis. Cranio. 1996;14:23-9.

31. Pereira MRV. Quantitative Auswertungen bildgebender Verfahren und Entwicklung einer neuen metrischen Analyse für Kiefergelenkstrukturen im Magnetresonanztomogramm: Verlag nicht ermittelbar; 1997.

32. Rabelo KA, Sousa Melo SL, Torres MGG, Peixoto LR, Campos PSF, Rebello I, et al. Assessment of condyle position, fossa morphology, and disk displacement in symptomatic patients. Oral Surg Oral Med Oral Pathol Oral Radiol. 2017:124:199-207.

33. Ishizaki K, Suzuki K, Mito T, Tanaka EM, Sato S. Morphologic, functional, and occlusal characterization of mandibular lateral displacement malocclusion. Am J Orthod Dentofacial Orthop. 2010;137(454):e1-9.

34. Jung SK, Kim TW. Treatment of unilateral posterior crossbite with facial asymmetry in a female patient with transverse discrepancy. Am J Orthod Dentofacial Orthop. 2015;148:154-64.

\section{Publisher's Note}

Springer Nature remains neutral with regard to jurisdictional claims in published maps and institutional affiliations. 